\title{
The Effects of Ginger Extract and Diazepam on Anxiety Reduction in Animal Model
}

\author{
Fatemeh Fadaki ${ }^{1}$, Mehrdad Modaresi ${ }^{2 *}$, Ilnaz Sajjadian' \\ ${ }^{1}$ Department of Psychology, Isfahan (Khorasgan) Branch, Islamic Azad University, Isfahan, IRAN \\ ${ }^{2}$ Department of Animal science, Isfahan (Khorasgan) Branch, Islamic Azad University, Isfahan, IRAN
}

\begin{abstract}
Objective: Anxiety disorders are from common disorders of human. Drug treatments have side effects, and searching new ways with fewer side effects is inevitable. Ginger is a medicinal plant with many therapeutic effects. Methods: In current study the effects of ginger extract and diazepam on anxiety reduction of laboratory mice were investigated. Sixty female mice $(25-30 \mathrm{~g})$ were divided into six groups including control, anxiety, diazepam and 50,100 and $200 \mathrm{mg} / \mathrm{kg}$ extract doses. After receiving the last dose, all groups except control group were placed in dark box to enforce anxiety. Next, anxiety evaluation test was carried out using plus elevated maze. The number of open and close arms were considered as anxiety indices. Results: According to results, ginger extract reduced anxiety in all doses in proportion to control and diazepam groups. Also, movement activity was increased in $200 \mathrm{mg} / \mathrm{kg}$ dose significantly $(\mathrm{p}<0.05)$. Conclusion: Therefore, ginger extract in $200 \mathrm{mg} / \mathrm{kg}$ dose can be an appropriate replacement for diazepam to reduce anxiety symptoms.
\end{abstract}

Keywords: Ginger, Anxiety, Diazepam, Plus elevated maze, Mice.

\section{INTRODUCTION}

Anxiety is a kind of internal response to threatening circumstances for spiritual and material situation of people. Anxiety disorders are the most common mental disorders so that the prevalence of anxiety is estimated about $10-30 \%$. For this reason, sedative and anti-anxiety drugs are frequently used. Since most of anti-anxiety drugs have soothing, hypnotic and relaxing effect on the muscles and organs, cause physical dependence and also mental addiction. ${ }^{1}$ Diazepam as an antianxiety benzodiazepam drug has proved effects on central nervous system and is famous as an anti-anxiety drug. Palliative and anti-anxiety effects of diazepam are because of interaction with Gaba receptors of brain particularly in the midbrain reticular formation. ${ }^{2}$ Side effects of diazepam are forgetfulness, severe drowsiness, slurred speech, bradycardia, dyspnea, ataxia, unusual bruising or bleeding and mouth ulcers. ${ }^{3}$ Sudden withdrawal of this drug causes withdrawal symptoms and appearance of benzodiazepine withdrawal syndrome. This syndrome has symptoms of anxiety, insomnia, irritability, tremors and seizures. Since active ingredients of herbal drugs are accompanied and balanced with other matters, are not accumulated in the body and don't have side effects, hence, have significant advantages compared to chemical drugs. ${ }^{4}$

On the other hand, world health organization (WHO) has frequently emphasized on necessity of scientific economical use of traditional medicine and herbal drugs. This approach is one of the most important issues in the world in recent decades, especially in developing countries. ${ }^{5}$ Nowadays, medicinal plants have been used more because of appearing numerous properties of them such as anti-oxidant activities and physiological aspects of them including anti-cancer, anti-sensitivity and anti-diabetic properties, prevention of coronary artery blockage, and reducing cholesterol. ${ }^{6}$ Reports exist about the Effect of flavonoids on
DOI: 10.5530/ijper.51.3s.4 Correspondence: Mehrdad Modaresi, Department of Animal science, Isfahan (Khorasgan) Branch, Islamic Azad University, Isfahan, IRAN

Contact: +989132074854

Fax: +983135354060

E-mail: mehrdad_modaresi@ hotmail.com 
benzodiazepines receptors. Extant flavonoids in medicinal plants cause tranquilizing, anti-anxiety effects via affecting benzodiazepine receptors binding to Gaba receptors. ${ }^{7}$

Ginger (Zingiber officinale) is a plant from Zingiberaceae family. Root of this plant is used as drug, spice and a delicious food. This plant has been used in traditional medicine of Iran as an anti-edema drug and is used for the treatment of various diseases including nausea, gastrointestinal disorders, respiratory disorders, atherosclerosis, migraine, depression, gastric ulcer, cholesterol. Other benefits of ginger are reducing pain, rheumatoid arthritis, anti-inflammatory, and antioxidant effects. ${ }^{8}$

Main pharmacological activities of ginger and its isolated compounds are immune modulators, anti-cancer, anti-tumor, anti-inflammatory, anti-apoptotic and antivomiting properties. This material is a strong anti-oxidant and prevents free radicals activity. ${ }^{9}$ Oxidative stress is one of chemical stresses which is caused by chemical stresses. Ginger extract can remove disorders caused by oxidative stresses as a strong anti-oxidant. ${ }^{10}$ Studies have showed that extant phenolic compounds and anthocyanins including gingerols and the sugevals had many neuro protective effects such as analgesic effects, memory improvement, and learning caused by the aging process. ${ }^{11}$

Considering that there are no extant study about antianxiety properties of ginger and also in view of prevalence of anxiety in population, side effects of chemical drugs and superiority of herbal drugs current study was carried out to investigate the effects of ginger extract and diazepam on anxiety reduction in mice.

\section{MATERIALS AND METHODS}

Sixty female mice from 25 to $30 \mathrm{~g}$ were divided into six groups with 10 mice in each group: control, anxiety, diazepam and 50,100 and $200 \mathrm{mg} / \mathrm{kg}$ extract doses. Mice were kept in a temperature, humidity controlled room with 12:12 $\mathrm{h}$ photo period. Samples had free access to food and water and $24 \mathrm{~h}$ before test were transferred to test place. To evaluate the anxiety, plus elevated maze was used which is recognized as standard model for this purpose. This apparatus has two open $\operatorname{arm}(1050 \mathrm{~cm})$ and two closed arms $(405010 \mathrm{~cm})$. Similar arms were opposite and $50 \mathrm{~cm}$ above ground.

Four parameters were evaluated: the number of entrance to open and closed arms and spent time in each arm. Significant increase in open arms entrance and spent time in this arm plus no movement activity shows anxiety reduction in this test. Obtained data were analyzed using SPSS 22 in both descriptive and inferential levels. In descriptive level average and standard deviation were calculated whereas one way analysis of variance was used in inferential level. Means were compared using Duncan test.

\section{RESULTS AND DISCUSSION}

Time spent in the open arms was significantly increased by $200 \mathrm{mg} / \mathrm{kg}$ dose in proportion to diazepam group. Movement activity of animals was also significantly higher than diazepam group. Duncan test showed that anxiety although reduced open arm entries significantly, the average of open arm entries in 100 and 200 doses were normal (about control group) and is similar to diazepam (Table 1).

Results showed that nervous mice had lower tendency to stay in open arms in proportion to control group. Ginger's extract increased the percentage of time spent in the open arms in proportion to control group, dose dependently. Mean comparisons showed that considering no significant difference between control, diazepam and $200 \mathrm{mg} / \mathrm{kg}$ group, average movement activity of mice in $200 \mathrm{mg} / \mathrm{kg}$ dose was normal (about control). Furthermore, anxiety reduces movement activity of mice significantly and average movement activity of 50 and $100 \mathrm{mg} / \mathrm{kg}$ groups were not significantly different from anxiety group. Anxiety is the most common mental disorder which appears by cognitive, physical, emotional and

\begin{tabular}{|c|c|c|c|c|c|c|}
\hline \multicolumn{2}{|c|}{ Table 1: Averages and standard deviations of variables in treatment groups } \\
\hline \multirow{2}{*}{ Group } & Open arm entries ratio & Time spent in the open arms & \multicolumn{2}{c|}{ Movement activity } \\
\cline { 2 - 7 } average & $\begin{array}{c}\text { standard } \\
\text { deviation }\end{array}$ & average & $\begin{array}{c}\text { standard } \\
\text { deviation }\end{array}$ & average & $\begin{array}{c}\text { standard } \\
\text { deviation }\end{array}$ \\
\hline Control & 55.32 & 6.92 & 36.26 & 9.00 & 15.50 & 1.90 \\
\hline Anxiety & 48.01 & 5.96 & 21.43 & 6.45 & 8.20 & 2.34 \\
\hline Diazepam & 54.58 & 4.26 & 46.69 & 6.20 & 13.60 & 3.09 \\
\hline $50_{\text {mgkg }}$ dose & 46.63 & 7.08 & 58.65 & 16.14 & 6.90 & 1.72 \\
\hline $100_{\text {mg/kg }}$ dose & 51.63 & 7.14 & 65.53 & 13.50 & 6.80 & 2.15 \\
\hline $200_{\mathrm{mg} / \mathrm{kg}}$ dose & 55.24 & 8.67 & 67.19 & 14.84 & 12.10 & 3.44 \\
\hline
\end{tabular}


behavioral components. Natural anxiety is a compromise - emotional response to stressful physiological and social stimuli which is experienced by people. Pathological anxiety is the most common psychological disorder which disrupts daily life and hurts human. ${ }^{3}$

In addition to drug therapies that their adverse effects are inevitable, using effective non-pharmacological methods and complement treatments are proposed to control clinical symptoms of anxiety. One of these methods is herbal medicine. ${ }^{12}$ From ancient times, herbal drugs have been used as therapeutic compounds with fewer side effects (10). Ginger is frequently used in traditional medicine. This plant is used as stimulant and carminative. It is also used to dispel the odor of some drugs. ${ }^{13}$ Gumar $e t$ al. Studied the effect of hydro alcoholic extract of ginger on hyoscine induced analgesia in male rats and announced that combination of ginger extract and hoisin caused more analgesia. They concluded that since hyoscine as an analgesic drug from anticholinergic drugs has side effects, combination of them can reduce the dosage and side effects of hyoscine despite having analgesic effects. ${ }^{5}$

In other study, Kiung et al. Studied anti-oxidant effect of ginger on immune system and showed that this plant prevented inflammatory diseases such as osteoarthritis and rheumatoid arthritis and reduced pain in these diseases by strengthening immune system. ${ }^{11}$ Considering the prevalence and importance of anxiety and existence of various species of this plant in different climates of Iran which their benefits mentioned in references and also in view of undesired side effects of chemical drugs plus patient addiction, in this study we tried to reduce anxiety symptoms by effective matters of ginger's extract. ${ }^{13}$ The important point of using herbal drugs is determining the appropriate dose with minimal side effects. For this reason, 50, 100 and $200 \mathrm{mg} / \mathrm{kg}$ doses were studied in this paper.

\section{CONCLUSION}

Results showed that extract in all doses increased time spent in the open arms significantly comparing to diazepam and control groups which indicates anxiety reduction. Also, $200 \mathrm{mg} / \mathrm{kg}$ dose increased movement activity of mice in proportion to diazepam significantly. So, we can conclude that ginger extract can reduce anxiety reactions dose dependently.

\section{ACKNOWLEDGEMENTS}

This study was supported by Isfahan (Khorasgan)

Branch, Islamic Azad University, Isfahan, Iran, and resulted from M.Sc thesis of Fatemeh Fadaki.

\section{CONFLICT OF INTEREST}

None

\section{ABBREVIATIONS USED}

WHO: World Health Organization; SPSS: Statistical package for social science.

\section{REFERENCES}

1. Atarodi A, Lotfi GR, Mottaghi M, Daemi A, Rohani Z. The Relationship between Coaching Anxiety with Footsal Players.' Anxiety and Performance in Gonabad City in 2010. Horizon Med Sci. 2011:17(3):58-66.

2. Basravi M, Modaresi M, Sajjadian I. Comparative effects of balm hydro alcoholic extract and diazepam on reducing anxiety in mice. Derpharmacia Lettre. 7(11):125-9.

3. Afshari TJ, Moheghi N, Brook A. Ethanolic Extract Cytotoxic Effect of Zingiber Officinale in Hepatocellular Carcinoma (HEPG2) Cell Line. Sci J Hamadan Univ Med Sci. 2010;17(3):52-6.

4. Dalvand Z, Modaresi M, Sajjadian I, The comparative effect of hydro alcoholic extract of passion flower and fluoxetine on depression symptoms in mice by forced swimming test. Der Pharma Chemica. 2016;8(16):112-5.

5. Ganiyu O, Ayodele J, Akinyemi AO. Antioxidant and Inhibitory effect of Red ginger (Zingiber officinale var. Rubra) and white ginger (Zingiber officinale Roscoe) on $\mathrm{Fe} 2+$ induced lipid peroxidation in rat brain in vitro. Exper Toxicol Pathol. 2012;64(1):31-6.

6. Rezaie A, Jafari B, Ahmadizadeh $\mathrm{CH}$. Hedayati JM, Ostadi Z. Study of Sedative Preanaesthetic and anxiolytic effects of herbal extract of Tilia platyphyllos scop in comparison with diazepam in the rat. Veterinary Journal of Tabriz. 2011;5(1):1051-8.

7. Modaresi M, Messripour M, Rajaei R. The Effect of Cinnamon (Bark) Extract on Male Reproductive Physiology in Mice Armaghane danesh. 2009;14(1):67-77.

8. Niksokhan M, Hedarieh N, Maryam N, Masoomeh N. Effect of hydro-alcholic extract of Pimpinella anisum seed on anxiety in male rat. J Gorgan Uni Med Sci. 2014;16(4):28-33.

9. Germezgoli S, Nasri S, Naseri M. Evaluating the Root Extract of Cyperus rotundus L. on Learning and Memory in Male Rats. SJIMU, 2015;22(6):34-43.

10. Modaresi M, Pouriyanzadeh A. Effect of Ocimum Basilicum Hydro Alcoholic Extract Against Pentylenetetrazole-Induced Seizure in Mice Armaghane danesh. 2013;18(8):615-21.

11. Piri M, Shahab Z, Shahin MS. Interaction between mecamylamine and nitric oxide in dorsal hippocampus using the elevated plus-maze test of anxiety. Feyz 2013;17(5):429-31.

12. Kyung KS, Gon JH, Geun KY, Sup JJ, Suk WJ, Ho KJ. 6-Shogaol, a natural product cell death and restores motor function in rat spinal cord injury. Eur $\mathrm{J}$ Neurosci. 2006:24(4):1042-52.

13. Riahkali RS, Pourmemari M, Mohammadi KT, Askandari F, Avazeh A. Study on Effective Factors on Patients' Family Members Anxiety in Intensive Care Units. ZUMS Journal. 2010;18(70):91-101. 


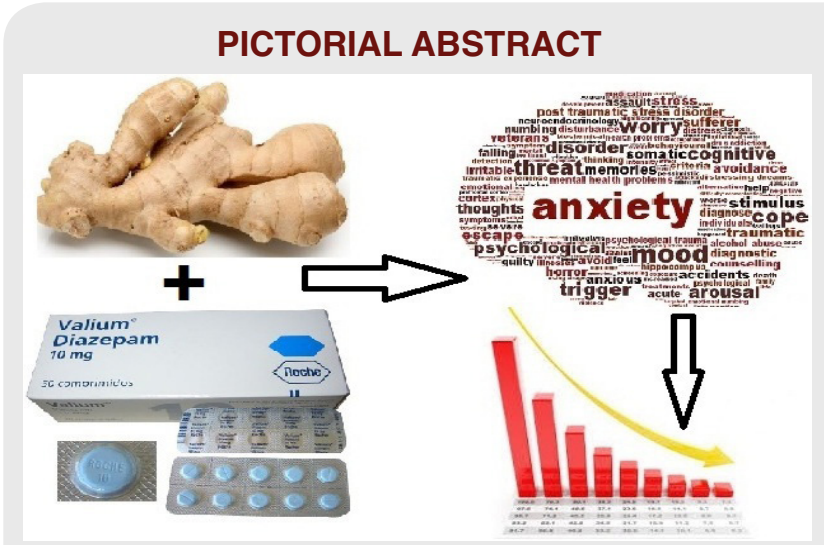

About Authors

\section{SUMMARY}

- Anxiety disorders are from common disorders of human.

- Ginger is a medicinal plant with many therapeutic effects.

- In current study the effects of ginger extract (50, 100 and $200 \mathrm{mg} / \mathrm{kg}$ ) and diazepam on anxiety reduction of laboratory mice were investigated.

- According to results, ginger extract reduced anxiety in 50,100 and $200 \mathrm{mg} / \mathrm{kg}$ doses in proportion to control and diazepam groups.

- Also, movement activity was increased in 200 mg/ $\mathrm{kg}$ dose significantly $(\mathrm{p}<0.05)$.

- Ginger extract in $200 \mathrm{mg} / \mathrm{kg}$ dose can be an appropriate replacement for diazepam to reduce anxiety symptoms.

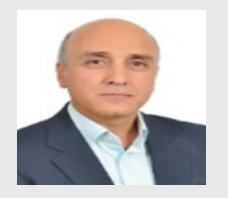

Mehrdad Modaresi (Ph.D in Animal Sciences): He is currently working as an Associate Professor in the Department of Animal Science at Islamic Azad University, Isfahan (Khorasgan) Branch, Isfahan, Iran; he extended his valuable service in field of Herbal drugs effects on Animal Physiology and Reproductive biology and has been a recipient of few awards and grants.

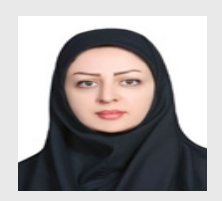

Fatemeh Fadaki (Ms.C in Psycology): She received a master's degree in psychology from the Islamic Azad University, Isfahan (Khorasgan) Branch, Isfahan, Iran and now works as a consultant psychologist.

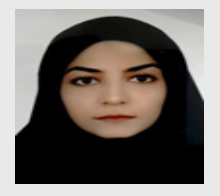

Ilnaz Sajjadian (Ph.D in Psycology): She is a faculty member of the Department of Psychology at the Islamic Azad University, Isfahan (Khorasgan) Branch, Isfahan, Iran.

Cite this article: Fadaki F, Modaresi M, Sajjadian I. The Effects of Ginger Extract and Diazepam on Anxiety Reduction in Animal Model. Indian J of Pharmaceutical Education and Research. 2017;51(3)Suppl:S159-62. 